\title{
Studies on Procamallanus (Spirocamallanus) pereirai Annereaux, 1946 (Nematoda: Camallanidae), with New Host Records and New Morphological Data on the Larval Stages
}

\author{
Cláudia Portes Santos ${ }^{+}$, Melissa Querido Cárdenas, Herman Lent
}

Universidade Santa Úrsula, ICBA, Rua Fernando Ferrari 75, 22231-040 Rio de Janeiro, RJ, Brasil

Larval stages and adults of Procamallanus (Spirocamallanus) pereirai Annereaux, 1946 are described from naturally infected Paralonchurus brasiliensis (Steindachner) (Sciaenidae) from the coast of the State of Rio de Janeiro, Brazil. The translucent first-stage larvae have a denticulate process at the anterior end, no buccal capsule or esophagus undifferentiated into anterior muscular and posterior glandular parts and an elongate tail; third-stage larvae have a tail with three terminal projections, a buccal capsule divided into an anterior portion with 12-20 ridges running to the left and a posterior smooth portion, and an esophagus with muscular and glandular regions. Fourth-stage larvae exhibit a buccal capsule lacking a distinct basal ring with ridges running to the right and a tail with two terminal processes, as in adults. New host records are reported and their role in its life-cycle are discussed.

Key words: Procamallanus (Spirocamallanus) pereirai - Nematoda - Camallanidae - larval stages - life-cycle fish - Brazil

During a survey of fish parasites off the northeast coast of the State of Rio de Janeiro, Brazil, different stages of the nematode Procamallanus (Spirocamallanus) pereirai Annereaux, 1946 were found in estuarine fishes. As camallanids are considered a significant problem for fishes when maintained in a closed ecosystem in the presence of suitable intermediate hosts (Rychlinski \& Deardorff 1982), the description of previously unknown larval stages and the new host records encountered aid on understanding of the biology of this nematode in the study area.

\section{MATERIALS AND METHODS}

Ninety-four fishes were accidentally captured in shrimp nets off the State of Rio de Janeiro, between Atafona $\left(21^{\circ} 37^{\prime} \mathrm{S}, 41^{\circ} 02^{\prime} \mathrm{W}\right)$ and Macaé ( $\left.22^{\circ} 23^{\prime} \mathrm{S}, 41^{\circ} 47^{\prime} \mathrm{W}\right)$. These were identified as: 32 Paralonchurus brasiliensis (Steindachner, 1875), 21 Macrodon ancylodon (Bloch \& Schneider, 1801), 16 Stellifer brasiliensis (Schulz, 1945), 15 Nebris microps (Cuvier, 1830), 6 Porichthys porosissimus (Valenciennes, 1937), 3 Symphurus tesselatus (Quoy \& Gaimard, 1824) and 1

\footnotetext{
This work was supported by the Conselho Nacional de Pesquisa $(\mathrm{CNPq})$ and Universidade Santa Úrsula. ${ }^{+}$Corresponding author. Fax: +55-21-5516446. E-mail: cpsantos@ax.apc.org

Received 27 January 1999

Accepted 7 June 1999
}

Menticirrus americanus (Linnaeus, 1758). Fishes were dissected shortly after capture, usually being freshly killed. During the necropsy, all organs were separated and placed in sieves of $200 \mu \mathrm{m}$ to be washed. Nematodes were fixed in Berland's fluid (Gibson 1979) for about $1 \mathrm{~min}$ and then stored in $70 \%$ alcohol. Drawings were made with the aid of a Wild microscope drawing attachment. Measurements were made with the use of a calibrated filar micrometer and are given in millimeters. The mean is indicated in parenthesis followed by the number of specimens measured, when more than two. Ecological terms used follow Margolis et al. (1982) and Moravec (1994). Helminths collected during the survey were deposited in the Helminthological Collection of Instituto Oswaldo Cruz, nos. 34.10734.110 (balsam) and 33.844-33.849 (alcohol).

\section{RESULTS}

The prevalence and abundance of $P$. $(S$.) pereirai in Paralonchurus brasiliensis was $78 \%$ and 2.7 , in $N$. microps, $66 \%$ and 2.3 ; in $S$. brasiliensis $6 \%$ and 0.06 , and in P. porosissimus $16 \%$ and 0.16 . All three S. tesselatus were parasitized with three, three and four nematodes, respectively, while the only specimen of $M$. americanus had one nematode. The following description is based on specimens from P. brasiliensis; measurements from other hosts are presented in the Table.

The first-stage larvae of these viviparous nematodes develop in the uterus of gravid females. The slender, colorless first-stage larvae, obtained from 


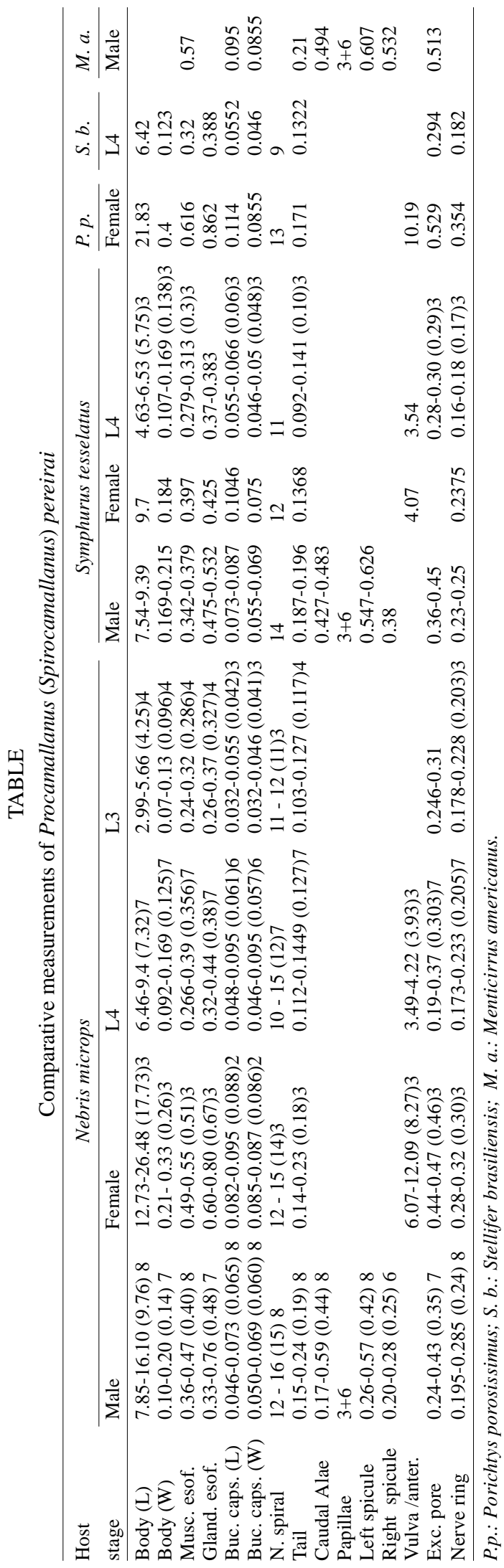

the uterus, measure $0.193-0.33$ (0.24) 13 in length by $0.011-0.016(0.012) 13$ in width and have a dorsal cuticular tooth in the head. The cuticle is thick, and transversely striated. The buccal capsule is absent and the buccal tube is slender. The esophagus is undivided and measures 0.049-0.076 $(0.055) 12$. The nerve-ring is at $0.025-0.046(0.036)$ 9 from the anterior end. The excretory pore was not observed. The long, sharply pointed tail measure 0.046 - 0.071 (0.061) 5 (Fig. 1). The secondstage larvae were not observed.

The third-stage larvae, found in the stomach and intestine of the fish host, are characterized by their tail bearing 3-4 terminal processes. Their total length is $1.66-4.07$ (2.64) 10 by $0.046-0.10$ (0.066) 10 wide (Fig. 2). They are colorless and the translucent buccal capsule, which measures $0.029-0.05$ by $0.025-0.041(0.035 \times 0.031) 10$, is clearly divided into an anterior part with 12-20 (17) 9 ridges running to the left and a posterior smooth part. The muscular and glandular regions of the esophagus are 0.12-0.27 (0.20) 10 and 0.10-0.28 (0.17) 9 long, respectively. The excretory pore and nerve-ring are at 0.15-0.24 (0.19) 7 and 0.10-0.17 (0.13) 4 from the anterior end, respectively (Fig. $3)$. The distance from anus to the tip of the tail is 0.043-0.12 (0.062) 9 (Fig. 4).

Fourth-stage larvae were found only in the intestine. They measure 4.15-11.57 (7.10) 9 in length by $0.061-0.184(0.123) 9$ in width. The buccal capsule, without a distinctly separated basal ring, measures 0.041-0.066 (0.054) 9 x 0.032-0.06 (0.045) 9 with 9-14 (12) 18 ridges running to the right (Fig. 5). There is a short esophageal cup at the base of buccal capsule. The muscular esophagus is $0.27-0.40(0.32) 10$ and the glandular one is $0.25-0.51(0.41) 9$. The excretory pore is at 0.27 $0.40(0.32) 6$ and the nerve ring is at $0.17-0.23$ (0.19) 8 from the anterior end. The tail is 0.08 0.167 (0.12) 8 long and bears a bifid tip as in the adults (Fig. 6).

Adults are characterized by their orange-brown, undivided, thick-walled buccal capsule with distinct basal ring and two terminal tips at the end of the tail in both sexes. Males are 7.61-14.42 (11.44) 11 long by $0.15-0.29(0.20) 11$ wide. The buccal capsule measures $0.064-0.085(0.070) 10$ in length by $0.052-0.066(0.059) 10$ in width, with 12-17 (14) 14 ridges. The muscular and glandular regions of the esophagus are $0.36-0.49(0.40) 10$ and $0.51-0.66$ (0.60) 9 , respectively. The nerve ring and excretory pore are at 0.16-0.26 (0.24) 10 and 0.33-0.53 (0.41) 8 , respectively, from the anterior extremity (Fig. 7). The posterior end of the body is provided with caudal alae 0.40 - $0.56(0.45) 9$ long; it bears 3 pairs of precloacal pedunculate papillae and 6 pairs of postcloacal papillae, 4 pairs being subventral and 2 pairs 

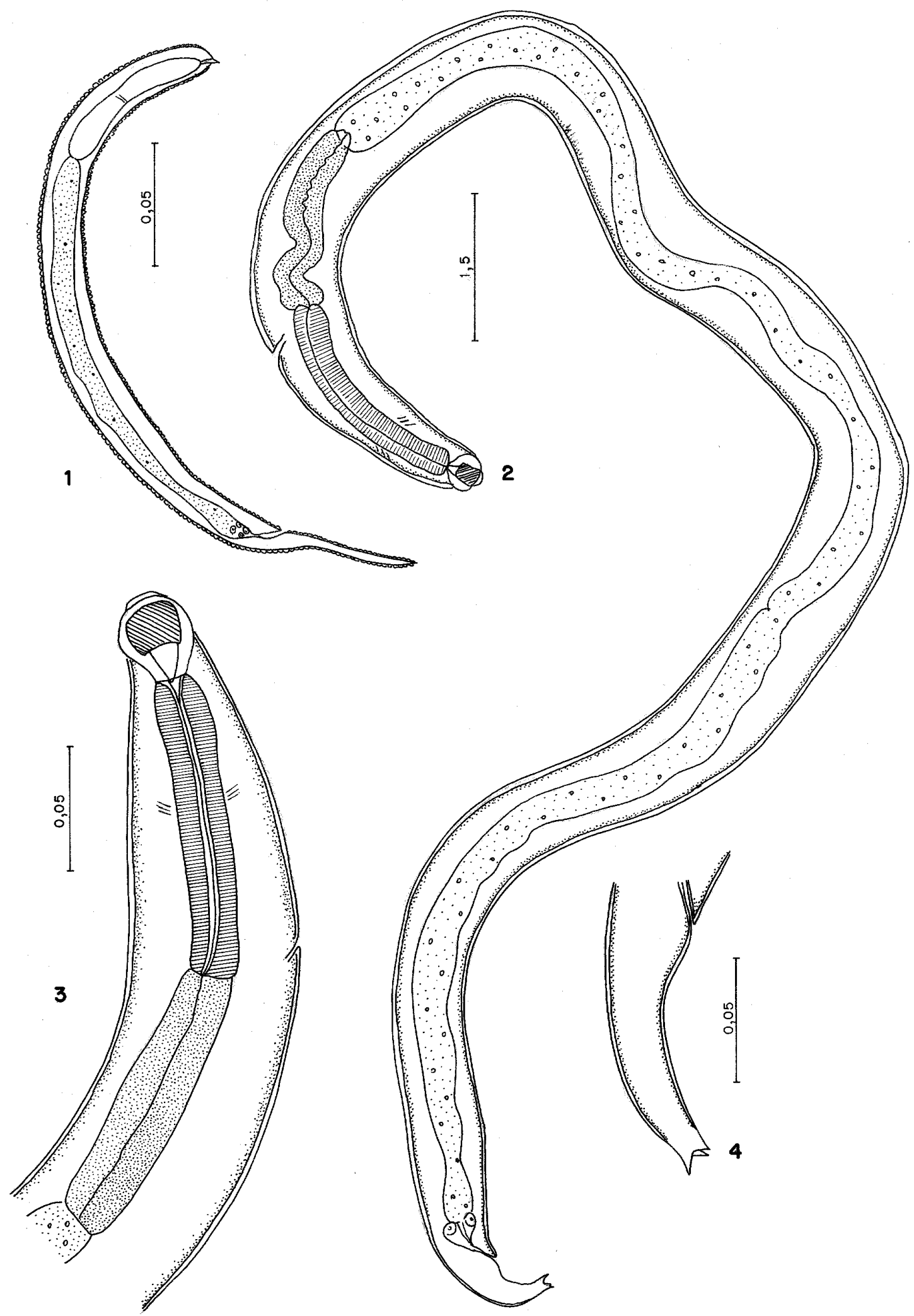

Procamallanus (Spirocamallanus) pereirai. Fig. 1: first-stage larva from uterus of a female. Fig. 2: general view of third-stage larva. Fig. 3: buccal capsule and esophagus of third-stage larva. Fig. 4: tail of third-stage larva. 
lateral. The right (larger) spicule is $0.30-0.57(0.49)$ 10 and the left one is $0.20-0.48(0.28) 8$. The gubernaculum is absent. The tail is conical and measures $0.16-0.25(0.19) 10$. It bends ventrally and has two terminal processes (Fig. 9).

Females are 13.22-31.23 (20.06) 11 in length by $0.29-0.52(0.33) 11$ in width (Fig. 8). The buccal capsule measures $0.08-0.10(0.09) 11$ x 0.070.09 (0.08) 12 and has 12-14 (13) 11 ridges. The length of the muscular and glandular regions of the esophagus are $0.44-0.58(0.51) 11$ and 0.57 $0.91(0.76) 11$, respectively. The excretory pore and the nerve-ring are at $0.30-0.53(0.40) 8$ and 0.19 $0.33(0.27) 11$ respectively from the anterior end. The vulva is at 6.74-12.3 (9.27) 11 from the anterior end. The tail is conical and measures 0.11-0.33 (0.18) 11 in length. It ends in two projections that are 0.041-0.057 (0.047) 9 long (Figs 8, 10).

\section{DISCUSSION}

$P$. (S.) pereirai was first described from the intestine of Atherinopsis californiensis from California by Anneureaux (1946). The adults of this nematode has subsequently been reported from a variety of hosts and different geographical localities (Soganders-Bernal 1955, Noble \& King 1960, Hutton 1964, Joy 1971, 1974, Corkern 1978, Yin 1983, Pinto et al. 1984, Vicente et al. 1985, Sood 1989, Frost \& Dailey 1994). The third-stage larva of this nematode was described from the intestine of white shrimps off Mississipi (Overstreet 1973). From the coast of the State of Rio de Janeiro, adults of $P$. (S.) pereirai have previously been reported from P. brasiliensis (Pinto et al. 1984, Vicente et al. 1985).

Previous authors, such as De (1995), Fusco (1980), Moravec (1994), Moravec et al. (1993, 1995), Moravec \& Vargas-Vasquez (1996), studied larval stages of different camallanids. In Brasil, the larval stages of Procamallanus (S.) hilarii Vaz \& Pereira, $1934(=P$. (S.) cearensis Pereira, Dias $\&$ Azevedo, 1936 were found in freshwater copepods and fish hosts by Pereira et al. (1936), and only in fishes by Moravec et al. (1993). The finding of a natural infection in different estuarine fishes in this study has revealed for the first time the first-stage larvae of $P$. (S.) pereirai. This stage is characterized by its translucent color, a dorsal cuticular tooth in the head, the absence of a buccal capsule, an esophagus undifferentiated into an anterior muscular and a posterior glandular regions, and an elongate tail. The second-stage larvae remains unknown, but it probably occurs in copepods, in view of the experimental infections of $P$. (S.) intestinecolas Bashirullah, 1973 and P. (S.) mysti (Karve, 1952) achieved in these host by Bashirullah and Ahmed (1973) and De (1995).

Overstreet (1973) described the third-stage larvae of $P$. (S.) pereirai from white shrimps Penaeus setiferus and from the spot Leiostomus xanthurus. These larvae were characterized as having a divided, translucent buccal capsule with ridges in the anterior region. The esophagus was already differentiated and the caudal end had four projections, similar to those of $P$. (S.) pimelodus Pinto, Fábio, Noronha \& Rolas, 1974 and $P$. (S.) mysti (Moravec et al. 1993, De 1995). It is not considered that the high number of ridges in five of ten of these larvae examined from $P$. brasiliensis is sufficient to consider it a third-stage larva of $P$. ( $S$.) macaensis Vicente \& Santos, 1972, the other species of the genus occurring in this area, since no adult of this species was found in any of the hosts examined.

Characteristic features of the fourth-stage larva of $P$. (S.) pereirai, described herein for the first time, are the buccal capsule, which lacks a distinct basal ring and ridges running to the right, and the caudal extremities with two terminal processes as in the adults.

The color of these nematodes can also be used as a differentiating character between adults and larval stages; while the third- and fourth-stage larvae are colorless, adults are reddish. This color was at first associated with the ingestion of blood (Noble \& King 1960, Joy 1974). Fusco (1978), however, demonstrated the presence of hemoglobin in camallanids distinct from those of the blood of the host, indicating that they probably feed on host food.

The infective third-stage larvae were found together with fourth-stage larvae and adults only in $P$. brasiliensis and N. microps. Therefore, $P$. brasiliensis and $N$. microps appear to be good definitive hosts for $P$. (S.) pereirai since they have all developmental stages from infective larva to adult. P. brasiliensis is apparently the most suitable host and harbored a large number of mature females, while $N$. microps had only one mature female. $S$. tesselatus yielded only fourth-stage larvae and adults and one adult nematode each was collected from the specimens of P. porosissimus and M. americanus examined. The term "paradefinitive" host was defined by Moravec (1998) in relation to the facultative host which partly substitutes the function of the definitive host, attaining the subadult stage without production of eggs or larvae. In this way, $S$. tesselatus, P. porosissimus and M. americanus could probably be paradefinitive hosts because no gravid female were found. The absence of larvae in $P$. porosissimus and $M$. americanus may be related to the small sample size. Only one fourth-stage larva was collected from 16 S. brasiliensis examined, and it is possible that this fish species represents just an eumetaparatenic host, a facultative host of helminth larvae in which there is no development (Moravec 1998). Among different hosts examined, $M$. ancylodon, a species which did not yield $P$. $(S$.) 

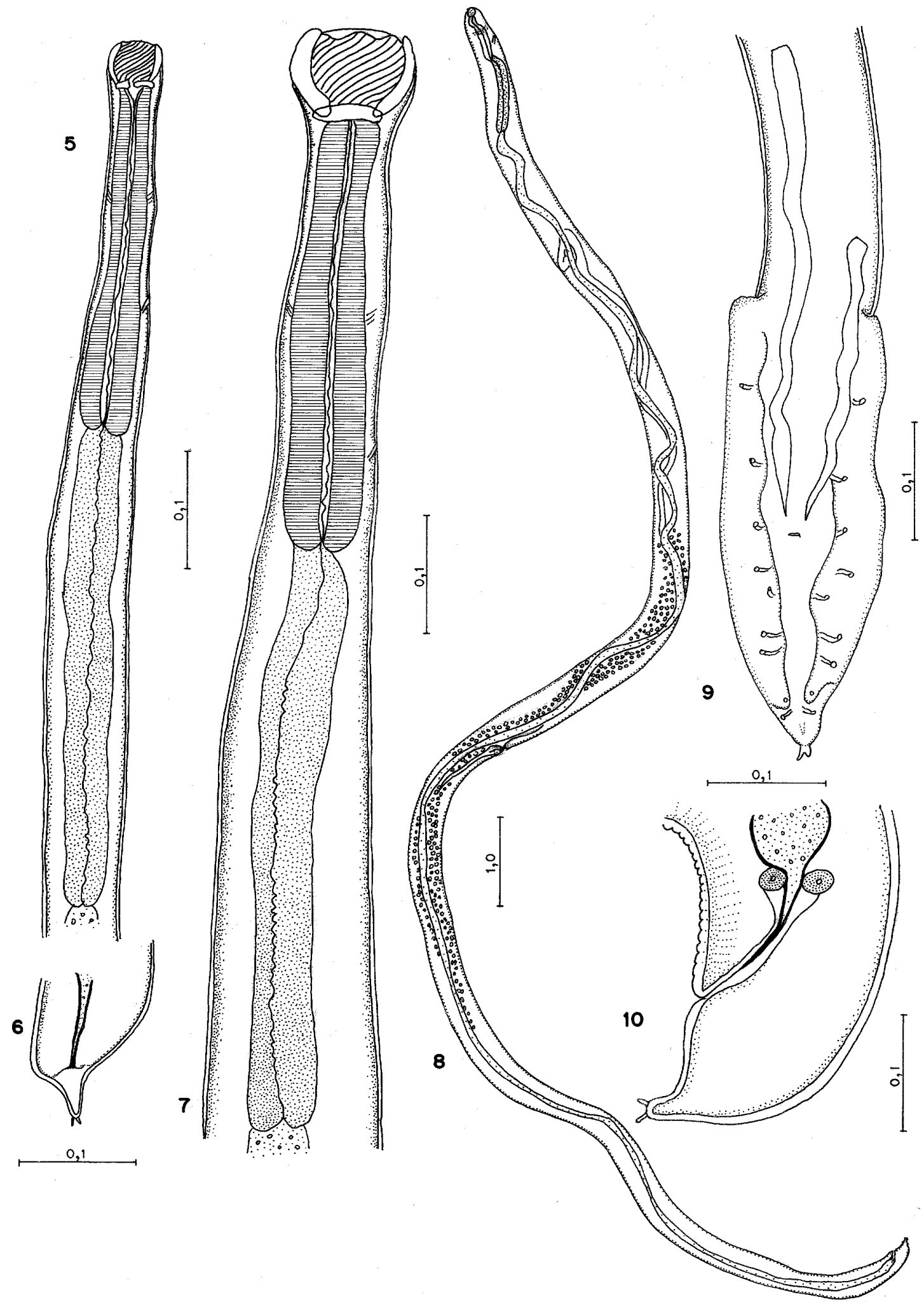

Procamallanus (Spirocamallanus) pereirai. Fig. 5: buccal capsule and esophagus of fourth-stage larva. Fig. 6: tail of fourth-stage larva. Fig. 7: anterior end of an adult female. Fig. 8: general view of female with vulva in posterior half of body. Fig. 9: tail of male. Fig. 10: tail of female. 
pereirai, was on the contrary expected to be another potential definitive host due to their preference for preying on P. brasiliensis among other fish (Juras \& Yamaguti 1985). Nevertheless, detailed knowledge of the association of these different hosts with $P$. (S.) pereirai will be ascertained only when its lifecycle can be fully developed in the laboratory.

Stellifer brasiliensis, Nebris microps, Porichthys porosissimus, Symphurus tesselatus and Menticirrus americanus are here reported as new host records for $P$. (S.) pereirai, and the new morphological data on one of the larval stages enhance our knowledge of this life-cycle in the wild.

\section{ACKNOWLEDGEMENTS}

To Renata Ramos and Ana Paula Di Beneditto from Universidade Estadual do Norte Fluminense for assistance in collecting fishes; Dr Frederico Kurtz from Santa Úrsula University for fish identification and Dr F Moravec from Institute of Parasitology, Academy of Sciences of the Czech Republic and Dr D I Gibson from The Natural History Museum for commenting on the manuscript.

\section{REFERENCES}

Annereaux RF 1946. A new Nematode, Procamallanus pereirai, with a key to the genus. Am Microsc Soc 65: 299-303.

Bashirullah AKM, Ahmed B 1976. Larval development of Spirocamallanus intestinecolas (Bashirullah, 1973) Bashirullah, 1974 in copepods. Riv Parassitol 37: 303-311.

Corkern CC 1978. Protozoan and metazoan symbionts of natural and maricultured populations of commercial shrimp from the northwestern coast of the Gulf of Mexico. Diss Abst Int B Sci Eng 38: 3509.

De NC 1995. On the development and life cycle of Spirocamallanus mysti (Nematoda: Camallanidae). Folia Parasitol 42: 135-142.

Frost PJ, Dayley MM 1994. Helminth parasites of some southern California fishes with a redescription of Proctoeces magnorus Manter, 1940 (Digenea: Fellodistomidae) and description of Choanodera meseri sp. n. (Digenea: Apocreadidae). Bull South California Acad Sci 93: 110-117.

Fusco AC 1978. Spirocamallanus cricotus (Nematoda): Isoelectric focusing and spectrophotometric characterization of its hemoglobin and that of its piscine host, Micropogonias undulatus. Exp Parasitol 44: 155-160.

Fusco AC 1980. Larval development of Spirocamallanus cricotus (Nematoda: Camallanidae). Proc Helminthol Soc Wash 47: 63-71.

Gibson DI 1979. Materials and methods in helminth alpha-taxonomy. Parasitology 79: xxxvi.

Hutton RF 1964. A second list of parasites from marine and coastal animals of Florida. Trans Am Microsc Soc 83: 439-447.

Joy JE 1971. Spirocamallanus pereirai (Nematoda: Camallanidae) from the croacker, Micropogonias undulatus, in Texas. J Parasitol 57: 390.

Joy JE 1974. Incidence and intensity of Spirocamallanus pereirai (Nematoda: Camallanidae) infections in the croaker, Micropogon undulatus (Linnaeus) and spot, Leiostomus xanthurus Lacèpéde, from Texas. Contr Mar Sci 18: 1-6.

Juras AA, Yamaguti N 1985. Food and feeding habits of king weakfish, Macrodon ancylodon (Bloch \& Schneider, 1801) caught in the southern coast of Brazil. Bol Inst Ocean 33: 149-157.

Margolis L, Esch GW, Holmes JC, Kuris AM, Schad GA 1982. The use of ecological terms in parasitology (report of an ad hoc commitee of the American Society of Parasitologists). J Parasitol 68: 131-133.

Moravec F 1994. Parasitic Nematodes of Freshwater Fishes of Europe, Academia and Kluwer Acad. Publishers, Prague and Dordrech, 473 pp.

Moravec F 1998. Nematodes of Freshwater Fishes of the Neotropical Region, Academy of Sciences of the Czech Republic, Ceské Budejovice, 464 pp.

Moravec F, Vargas-Vasquez J 1996. The development of Procamallanus (Spirocamallanus) neocaballeroi $(\mathrm{Ne}-$ matoda: Camallanidae), a parasite of Astyanax fasciatus (Pisces) in Mexico. Folia Parasitol 43: 61-70.

Moravec F, Kohn A, Fernandes BMM 1993. Nematode parasites of fishes of the Paraná river. Part 3. Camallanoidea and Dracunculoidea. Folia Parasitol 42: 211-229.

Moravec F, Mendoza-Franco E, Vargas-Vasquez J, Vivas-Rodriguez C 1995. Studies on the development of Procamallanus (Spirocamallanus) rebecae (Nematoda: Camallanidae), a parasite of cichlid fishes in Mexico. Folia Parasitol 31: 159-188.

Moravec F, Vivas-Rodríguez C, Scholz T, VargasVázquez J, Mendoza-Franco E, Gonzáles-Solís D 1995. Nematodes parasitic in fishes of cenotes (= sinkholes) of the Peninsula of Yucatan, Mexico. Part 1. Adults. Folia Parasitol 42: 115-129.

Noble ER, King RE 1960. The ecology of the fish Gillichthys mirabilis and one of its nematode parasites. J Parasitol 46: 670-685.

Overstreet RM 1973. Parasites of some penaeid shrimps with emphasis on reared hosts. Aquaculture 2: 105140.

Pereira C, Dias MV, Azevedo P 1936. Biologia do nematoide "Procamallanus cearensis" n. sp. Arch Inst Biol 7: 209-226.

Pinto RM, Vicente JJ, Noronha D 1984. First report of Ascarophis van Beneden, 1871: A. brasiliensis n. sp. (Nematoda, Ascarophidinae) and Procamallanus (Spirocamallanus) pereirai Annereaux, 1946 (Nematoda, Procamallaninae) in South America. Mem Inst Oswaldo Cruz 79: 491-494.

Rychlinski RA, Deardorff TL, 1982. Disease prevention and control. Spirocamallanus: a potential fish health problem. Fresh Mar Aquar 5: 22-23, 79-83.

Soganders-Bernal F 1955. Some helminth parasites of fresh and brackish water fishes from Louisiana and Panama. J Parasitol 41: 587-594.

Sood ML 1989. Fish Nematodes from South Asia, Kalyani Publishers, New Dehli, 704 pp.

Vicente JJ, Rodrigues HO, Gomes DC 1985: Nematóides do Brasil. 1 1 a parte: Nematóides de peixes. Atas Soc Biol Rio de Janeiro 25: 1-79.

Yin WZ 1983. On some nematodes from marine fishes in Hainan Island, China. Acta Zoot Sin 8: 225-228. 